\title{
Guidelines for the rational design of Ni-based double hydroxide electrocatalysts for the oxygen evolution reaction
}

Diaz Morales, O.A.; Ledezma Yanez, I.D.; Koper, M.T.M.; Calle Vallejo, F.

\section{Citation}

Diaz Morales, O. A., Ledezma Yanez, I. D., Koper, M. T. M., \& Calle Vallejo, F. (2015). Guidelines for the rational design of Ni-based double hydroxide electrocatalysts for the oxygen evolution reaction. Acs Catalysis, 5(9), 5380-5387. doi:10.1021/acscatal.5b01638

Version: $\quad$ Publisher's Version

License: $\quad$ Licensed under Article 25fa Copyright Act/Law (Amendment Taverne)

Downloaded from: https://hdl.handle.net/1887/3196743

Note: To cite this publication please use the final published version (if applicable). 


\title{
Guidelines for the Rational Design of Ni-Based Double Hydroxide Electrocatalysts for the Oxygen Evolution Reaction
}

\author{
Oscar Diaz-Morales, Isis Ledezma-Yanez, Marc T. M. Koper,* and Federico Calle-Vallejo* \\ Leiden Institute of Chemistry, Leiden University, P.O. Box 9502, 2300 RA Leiden, The Netherlands
}

Supporting Information

ABSTRACT: The oxygen evolution reaction (OER) is one of the major bottlenecks hindering the implementation of a global economy based on solar fuels. It is known that Ni-based catalysts exhibit remarkable catalytic activities for the OER in alkaline media. In this joint theoreticalexperimental study, we provide a thorough characterization of $\mathrm{Ni}$-based double hydroxides with $\mathrm{Cr}, \mathrm{Mn}, \mathrm{Fe}, \mathrm{Co}, \mathrm{Cu}$, and $\mathrm{Zn}$ at the atomic scale that not only explains the reasons for their high activity but also provides simple design principles for the enhancement of their electrocatalytic properties. Our approach, based on the local symmetry and composition of the active sites, helps rationalize the effect of dopants on the catalytic activity of $\mathrm{Ni}(\mathrm{OH})_{2}$. In particular, $\mathrm{NiFe}, \mathrm{NiCr}$, and $\mathrm{NiMn}$ double hydroxides (DHs) have superior catalytic activity, which reduce the OER potential to reach $0.5 \mathrm{~mA} \mathrm{~cm}{ }^{-2}$ by 230,190 , and $160 \mathrm{mV}$, respectively, in
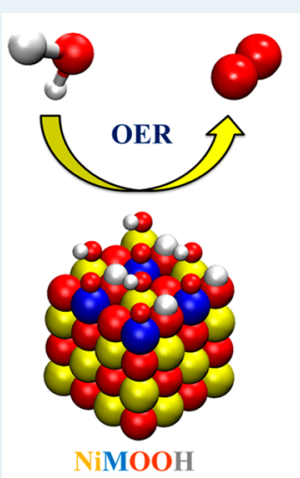

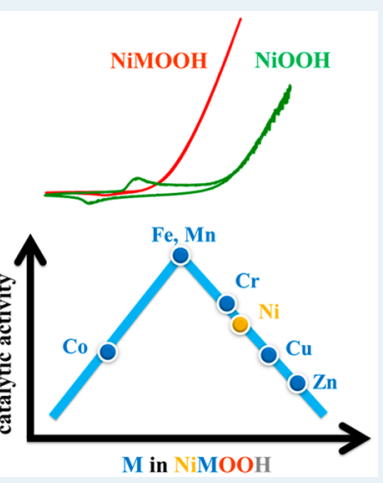

$\mathrm{M}$ in $\mathrm{NiMOOH}$ comparison to $\mathrm{IrO}_{2}$ nanoparticles, the state-of-the-art benchmarking catalysts, with $90 \%$ Faradaic efficiency for $\mathrm{O}_{2}$ generation. The active species in NiFe and NiMn DHs are iron and manganese, while in $\mathrm{NiCr} \mathrm{DH}$, nickel is the active species.

KEYWORDS: oxygen evolution reaction, nickel double hydroxides, transition-metal doping, cyclic voltammetry, rotating-disk electrode, electrocatalysis, density functional theory, volcano plot

\section{INTRODUCTION}

Fossil fuels have played a central role in the development of society since the beginning of the industrial revolution in the 18th century, powering factories and related technologies and transportation networks that drive and sustain modern civilization. However, the world population has tremendously increased since then, with a concomitant increase in energy needs. ${ }^{1}$ This has turned the availability of fossil fuels into an issue for future generations. In addition, the combustion of fossil fuels is environmentally harmful and is responsible for serious public health problems related to the reduction of air quality. ${ }^{1-3}$ Furthermore, recent studies suggest that the increase of the global average temperature should not exceed $2{ }^{\circ} \mathrm{C}$, which may only be achieved by drastic reductions of $\mathrm{CO}_{2}$ emissions associated with burning coal, oil, and natural gas, added to the widespread use of alternative sources of energy. ${ }^{4}$ Among those, sunlight is by far the largest exploitable resource. ${ }^{5}$ The transformation of solar energy into chemical energy is promising, ${ }^{3,5-7}$ as the electrons generated by (photo)electrochemical oxygen evolution can be used to drive, for instance, the electrochemical reduction of protons or carbon dioxide into fuels. An additional benefit of such a process is that water and oxygen are the main byproducts.

Nevertheless, one of the major bottlenecks hampering the application of solar power as a widespread energy source is the slow kinetics of the oxygen evolution reaction (OER). The overpotential of this reaction significantly reduces the overall efficiency of energy conversion. 8 Numerous catalysts have been studied to accelerate the water oxidation reaction, but the most active compounds are based on scarce, hence expensive, compounds such as $\mathrm{IrO}_{2}$ and $\mathrm{RuO}_{2} \cdot{ }^{10-12}$ Alternatively, catalysts based on earth-abundant transition metals have been proposed, showing intrinsic activity toward OER in alkaline media comparable to and even higher than that the iridium- and ruthenium-based catalysts. ${ }^{9,12-17}$ Those catalysts are mainly based on nickel or cobalt oxides, the activity of which has been rationalized through DFT calculations. ${ }^{17,18}$

Materials based on nickel hydroxide have also been studied, displaying good catalytic activity for oxygen evolution in alkaline media. ${ }^{13,14,16,19-21}$ It has been reported that the catalytic activity of nickel hydroxide can be significantly enhanced by modifying it with other transition metals such as chromium and iron, ${ }^{13,20-22}$ and the intrinsic catalytic activity of $\mathrm{NiFe}$ double hydroxides (from here on denoted DHs) toward oxygen evolution in alkaline media has been shown to be considerably higher than that of iridium-based catalysts. ${ }^{14,16,23,24}$ However, there have been no systematic attempts to understand the correlation between the activity of nickelbased double hydroxides toward water oxidation and the nature of the added transition metals. Furthermore, a comparison between different literature reports on the experimental activity of DHs is not straightforward due to the differences in the ways of benchmarking the catalytic activity. ${ }^{14,21}$

Received: May 14, 2015

Published: August 3, 2015 
We present here a theoretical and experimental study of the electrocatalytic properties of nickel-based double hydroxides with $3 \mathrm{~d}$ transition metals for the OER in alkaline media. This work gives a systematic study of the effect of transition-metal doping on the activity of nickel-based catalysts. The joint analysis of theoretical and experimental results is generally more accurate and insightful when multiple materials are compared, ${ }^{18,25}$ which is why we have established some theoretical trends in catalytic activity for a given family of compounds, synthesized all of them by means of the same method, and measured their experimental activities under identical conditions. The trends are rationalized in terms of the local symmetry and composition of the active sites and aim at providing simple and general design rules in OER electrocatalysis.

\section{COMPUTATIONAL AND EXPERIMENTAL DETAILS}

DFT Calculations. The DFT calculations were performed with the Vienna ab initio simulation package, ${ }^{26}$ using the RPBE exchange-correlation functional ${ }^{27}$ and ultrasoft pseudopotentials. ${ }^{28}$ Such a functional and pseudopotentials allow for straightforward comparisons with previous works. ${ }^{18}$ The simulations were made with four-layer slabs: the two top layers were free to move in all directions, while the two bottom layers were fixed at the ground-state bulk distances. The relaxations were carried out with the quasi-Newton scheme using as the convergence criterion a maximum residual force on any atom of $0.05 \mathrm{eV} \AA^{-1}$. In the low-coverage calculations the adsorbates were free to move in all directions, while in certain highcoverage calculations the $x$ or $y$ directions were constrained. The simulated $2 \times 2(001)$ monoxide slabs with a $4 \times 4 \times 1 k$ point mesh and a plane-wave cutoff of $450 \mathrm{eV}$ ensured convergence of the adsorption energies within $0.05 \mathrm{eV}$. The monoxides were simulated in the rock salt structure. We added $15 \AA$ of vacuum between periodically repeated images and applied dipole corrections. The Methfessel-Paxton method was used to smear the Fermi level ${ }^{29}$ with $k_{\mathrm{B}} T=0.1 \mathrm{eV}$, and all energies were extrapolated to $0 \mathrm{~K}$. The gas-phase molecules $\left(\mathrm{H}_{2}, \mathrm{H}_{2} \mathrm{O}\right)$ were calculated in boxes of $15 \times 15 \times 15 \AA, k_{\mathrm{B}} T=$ $0.001 \mathrm{eV}$, and a $1 \times 1 \times 1 k$-point mesh. The free energies are approximated as follows: $G=E_{\mathrm{DFT}}+\mathrm{ZPE}-\mathrm{TS}$, where $E_{\mathrm{DFT}}$ and $\mathrm{ZPE}$ are the total and zero-point electronic energies calculated through DFT, and TS are entropic contributions (only taken into account for gas-phase species). The ZPEs in $\mathrm{eV}$ for $\mathrm{H}_{2}, \mathrm{H}_{2} \mathrm{O}, * \mathrm{O}, * \mathrm{OH}$, and $* \mathrm{OOH}$ are respectively 0.27 , $0.56,0.07,0.34$, and 0.40 . The TS corrections in $\mathrm{eV}$ for $\mathrm{H}_{2}$ and $\mathrm{H}_{2} \mathrm{O}(\mathrm{l})$ are 0.40 and $0.67 \mathrm{eV}, 30,31$ respectively. In order to describe the energetics of solvated protons and electrons and to estimate overpotentials, we used the computational hydrogen electrode. ${ }^{31}$ The procedure for estimating the free energies of adsorption of $* \mathrm{O}, * \mathrm{OH}$, and $* \mathrm{OOH}$, which are the considered oxygen evolution intermediates, a brief discussion on solvation, and details of the construction of the volcano plots are given in section S8 in the Supporting Information and have also been given elsewhere. ${ }^{18,30}$ The active sites on the (001) facet are illustrated in Figure 1. The (001) surfaces of the monoxides ( $\mathrm{MO}$ with $\mathrm{M}=\mathrm{Ca}-\mathrm{Cu}$ ) were initially simulated (Figure 1.a). Furthermore, the surface layer of a $\mathrm{NiO}$ substrate was partially hydrogenated and doped with $\mathrm{Cr}, \mathrm{Mn}, \mathrm{Fe}, \mathrm{Co}, \mathrm{Ni}, \mathrm{Cu}$, and $\mathrm{Zn}$ (Figure 1.b), so as to model oxyhydroxide (NiMOOH) sites. To date, there are no clear conclusions in the literature about the actual surface morphology of $\mathrm{Ni}$ (oxy)hydroxides with and without Fe doping. This holds for theoretical as well as

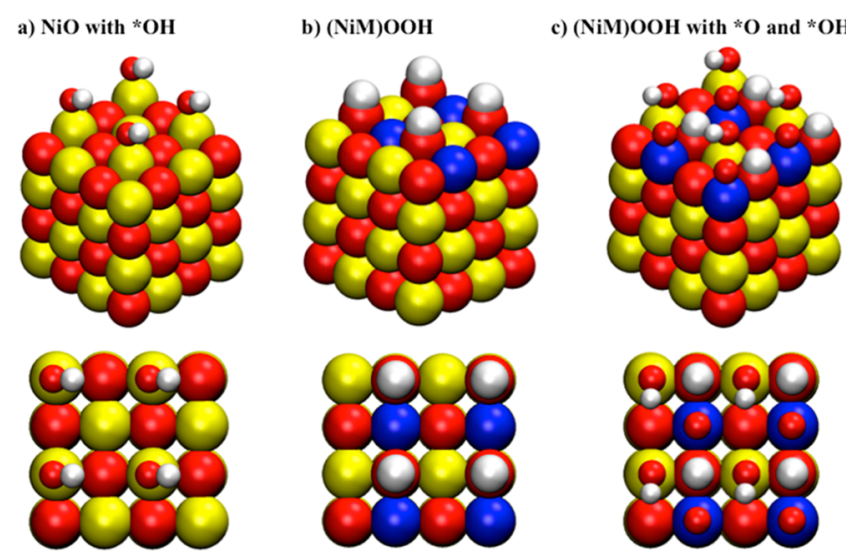

Figure 1. Perspective and top views of the active sites at (001) surface facets of the oxides under study. In this surface facet, octahedral $\mathrm{NiO}_{6}$ and $\mathrm{MO}_{6}$ complexes are formed. $\mathrm{Ni}$ atoms appear in yellow, oxygen atoms in red, $\mathrm{M}$ atoms in blue (where $\mathrm{M}$ can be $\mathrm{Cr}, \mathrm{Mn}, \mathrm{Fe}, \mathrm{Co}, \mathrm{Ni}$, $\mathrm{Cu}$, and $\mathrm{Zn}$ ), and $\mathrm{H}$ atoms in white. For convenience, $\mathrm{O}$ and $\mathrm{H}$ atoms in the lattice (large) and adsorbed (small) have been drawn with different radii. (a) $\mathrm{NiO}$ with $* \mathrm{OH}$ adsorbed on $\mathrm{Ni}$. (b) Clean $\mathrm{NiMOOH}$. This structure contains $50 \% \mathrm{M}$ in the top layer and one of the oxygen atoms has been hydrogenated. (c) The same as in (b) with *O on $\mathrm{M}$ and ${ }^{*} \mathrm{OH}$ on $\mathrm{Ni}$, corresponding to the active sites under OER conditions.

experimental studies. In fact, various authors have claimed that, under reaction conditions, different oxyhydroxide phases compose the exposed surfaces. For instance, Bell and coworkers $^{24}$ claim that Fe doping enhances the activity of the (01 - 12) plane of $\gamma-\mathrm{NiOOH}$, while $\mathrm{Li}$ and Selloni ${ }^{32}$ attribute the activity to the $(01-15)$ plane of $\beta-\mathrm{NiOOH}$.

In any case, the EXAFS experiments of Bell and co-workers ${ }^{24}$ reveal valuable information: both metals in $\mathrm{NiFeOOH}$ form octahedral complexes of the type $\mathrm{NiO}_{6}$ and $\mathrm{FeO}_{6}$. This is the reason we have used bulk nickel monoxide $(\mathrm{NiO})$ to build our surfaces, as it contains octahedral metal centers surrounded by six oxygen ligands $\left(\mathrm{NiO}_{6}\right)$. Moreover, we have hydrated one of the surface oxygen atoms and doped with $\mathrm{Cr}, \mathrm{Mn}, \mathrm{Fe}, \mathrm{Co}, \mathrm{Ni}$, $\mathrm{Cu}$, and $\mathrm{Zn}$ (Figure 1.b) so that the composition of the top layer of a $2 \times 2$ unit cell is $\mathrm{NiMOOH}$. In that way, we can reproduce in our model the only two certain experimental observations of $\mathrm{Ni}$ oxides under OER conditions. (i) The surface is partially dehydrated, so that hydroxides turn into oxyhydroxides. (ii) The metal centers form $\mathrm{MO}_{6}$ and $\mathrm{NiO}_{6}$ complexes. In broad terms, the use of hydrogenated $\mathrm{NiO}$ is as arbitrary as the use of $\gamma-\mathrm{NiOOH}$ or $\beta-\mathrm{NiOOH}$ until further conclusive experimental evidence is obtained. This choice ensures, therefore, that the local symmetry of the catalyst is reproduced, in spite of the lack of precise information on the catalyst's surface morphology. The OER activity of these sites was modeled at a high coverage of oxygenated species (see Figure 1c and full details in Figure $S 7$ in the Supporting Information), and all calculations were spin-unrestricted. For each system, ferromagnetic and antiferromagnetic calculations (with spin alignment planes on the (111) and (100) planes) were carried out. Note that $\mathrm{MnO}, \mathrm{FeO}, \mathrm{CoO}$, and $\mathrm{NiO}$ are antiferromagnetic oxides. In particular, $\mathrm{NiO}$ has spin alignment in the (111) plane. $^{24}$

Chemicals. The following reagents were utilized: $\mathrm{Ni}$ $\left(\mathrm{NO}_{3}\right)_{2} \cdot 6 \mathrm{H}_{2} \mathrm{O}$ (Sigma-Aldrich, purum p.a., crystallized, $\geq 97.0 \%$ (KT)), $\mathrm{Cr}\left(\mathrm{NO}_{3}\right)_{3} \cdot 9 \mathrm{H}_{2} \mathrm{O}$ (Sigma-Aldrich, puriss p.a., $\geq 98.0 \%$ ), $\mathrm{Mn}\left(\mathrm{NO}_{3}\right)_{2} \cdot x \mathrm{H}_{2} \mathrm{O}$ (Alfa Aesar, metal basis, $\geq 97.0 \%$ ), 
$\mathrm{CoCl}_{2} \cdot 6 \mathrm{H}_{2} \mathrm{O}$ (Sigma-Aldrich, purum p.a., crystallized, $\geq 98.0 \%$ $(\mathrm{KT})), \mathrm{Fe}\left(\mathrm{NO}_{3}\right)_{3} \cdot 9 \mathrm{H}_{2} \mathrm{O}$ (Sigma-Aldrich, ACS reagent, $\geq 98 \%$ ), $\mathrm{Cu}\left(\mathrm{NO}_{3}\right)_{2} \cdot 3 \mathrm{H}_{2} \mathrm{O}$ (Sigma-Aldrich, purum p.a., 98.0-103\% $(\mathrm{KT})), \mathrm{Zn}\left(\mathrm{NO}_{3}\right)_{2} \cdot 6 \mathrm{H}_{2} \mathrm{O}$ (Sigma-Aldrich, reagent grade, $98 \%$ ), $\mathrm{Na}_{2} \mathrm{CO}_{3} \cdot 10 \mathrm{H}_{2} \mathrm{O}$ (Merck, pro analysis), $\mathrm{KOH}$ (SigmaAldrich, semiconductor grade, pellets, $99.99 \%$ trace metal basis), EtOH (Sigma-Aldrich, puriss. p.a., absolute, $\geq 99.8 \%$ (GC)), Nafion (Sigma-Aldrich, 5 wt \% in lower aliphatic alcohols and $15-20 \%$ water). All chemicals were used as received, unless otherwise stated. The water used in all experiments was deionized and ultrafiltrated by a Millipore Milli-Q system (resistivity $>18.2 \mathrm{M} \Omega \mathrm{cm}$ and TOC $<5 \mathrm{ppb}$ ).

Cleaning Procedure. The glassware was thoroughly cleaned before the experiments by boiling in a $1 / 3$ mixture of concentrated $\mathrm{HNO}_{3}$ and concentrated $\mathrm{H}_{2} \mathrm{SO}_{4}$ to remove organic contaminations. After this initial treatment, the glassware was boiled five times in water. When not in use, it was stored in an aqueous solution of $0.5 \mathrm{M} \mathrm{H}_{2} \mathrm{SO}_{4}$ and $1 \mathrm{~g} / \mathrm{L}$ $\mathrm{KMnO}_{4}$. For removal of the permanganate, the glassware was rinsed thoroughly with water and then immersed in a $1 / 1$ solution of concentrated $\mathrm{H}_{2} \mathrm{SO}_{4}$ and $30 \% \mathrm{H}_{2} \mathrm{O}_{2}$ to remove all particles of $\mathrm{MnO}_{2}$. Afterward, it was rinsed with water again and boiled five times in water.

Synthesis of the Nickel Double Hydroxides. All double hydroxides $(\mathrm{DH})$ were prepared by the coprecipitation route, ${ }^{33}$ using $0.1 \mathrm{M}$ solutions of $\mathrm{Ni}\left(\mathrm{NO}_{3}\right)_{2}$ and $\mathrm{M}\left(\mathrm{NO}_{3}\right)_{n}\left(\mathrm{M}^{n+}=\mathrm{Cr}^{3+}\right.$, $\left.\mathrm{Mn}^{2+}, \mathrm{Fe}^{3+}, \mathrm{Co}^{2+}, \mathrm{Cu}^{2+}, \mathrm{Zn}^{2+}\right)$ as precursors. The precipitation was performed at $80{ }^{\circ} \mathrm{C}$ by dropping $32 \mathrm{~mL}$ of the solution with the metals in $1 / 1$ molar ratio over $10 \mathrm{~mL}$ of water previously adjusted to $\mathrm{pH} 9$ with $0.1 \mathrm{M} \mathrm{Na}_{2} \mathrm{CO}_{3}$. The $\mathrm{pH}$ was kept approximately constant at 9 during the synthesis by simultaneous dropping of $0.1 \mathrm{M} \mathrm{Na}_{2} \mathrm{CO}_{3}(36 \mathrm{~mL})$. The addition of the $\mathrm{Ni}^{2+} / \mathrm{M}^{n+}$ solution and the $\mathrm{Na}_{2} \mathrm{CO}_{3}$ was complete within $1.5 \mathrm{~h}$, after which the suspension was filtered through glass and thoroughly rinsed with water. The powders were subsequently dried overnight at $120^{\circ} \mathrm{C}$ and finely ground.

Nickel(II) hydroxide was prepared by dropping $15 \mathrm{~mL}$ of 2 $\mathrm{M} \mathrm{NaOH}$ over $50 \mathrm{~mL}$ of $0.1 \mathrm{M} \mathrm{Ni}\left(\mathrm{NO}_{3}\right)_{2}$. The suspension was filtered through glass and thoroughly rinsed with water. The powders were subsequently dried overnight at $120{ }^{\circ} \mathrm{C}$ and finely ground.

Characterization. Powder X-ray diffraction (XRD) measurements were performed in a Philips X'Pert diffractometer, equipped with the $\mathrm{X}^{\prime}$ Celerator, using $\mathrm{Cu} \mathrm{K} \alpha$ radiation. The collection was done in the range $10^{\circ}<2 \theta<100^{\circ}$ in steps of $0.020^{\circ}(2 \theta)$ with a counting time of $10 \mathrm{~s} / \mathrm{step}$.

Fourier transform infrared (FTIR) measurements were performed using an IRAffinity-1S FTIR spectrophotometer from Shimadzu. The machine is equipped with a high-energy ceramic light source, a temperature-controlled, high-sensitivity DLATGS detector, a Michelson interferometer $\left(30^{\circ}\right.$ incident angle), and a spectral resolution of $0.6 \mathrm{~cm}^{-1}$.

The real composition of all nickel-based double hydroxides was measured by means of inductively coupled plasma atomic emission spectroscopy (ICP-AES). To carry out these measurements, the samples were dissolved in aqua regia $(3 / 1$ concentrated $\mathrm{HCl} /$ concentrated $\mathrm{HNO}_{3}$ ). The analysis was performed with a Varian Vista-MPX CCD Simultaneous ICPAES instrument.

Electrochemical measurements were carried out in a threeelectrode, two-compartment cell with the reference electrode separated by a Luggin capillary. The working electrode over which the catalyst was supported was an $\mathrm{Au}$ rotating-disk electrode (RDE) with a diameter of $4.6 \mathrm{~mm}$, and all experiments were performed at $1500 \mathrm{rpm}$. The counter electrode was a gold spiral, and a reversible hydrogen electrode (RHE) was used as the reference electrode. Unless stated, all potentials in this work are referenced to the RHE scale. A platinum wire was connected to the reference electrode through a $10 \mu \mathrm{F}$ capacitor, acting as a low-pass filter to reduce the noise in the low-current measurements. Electrochemical measurements were performed with a PGSTAT12 potenstiostat (Metrohm-Autolab). Before and between measurements, the $\mathrm{RDE}$ electrode was first polished with 0.3 and $0.05 \mu \mathrm{m}$ alumina paste (Buehler Limited). Subsequently, the electrode was sonicated for $5 \mathrm{~min}$ in water to remove alumina particles. The OER measurements were conducted with cyclic voltammetry at $0.01 \mathrm{~V} \mathrm{~s}^{-1}$ in solutions saturated with $\mathrm{Ar}$, bubbled at least $30 \mathrm{~min}$ prior to the electrochemical experiments.

The double hydroxides were immobilized on the electrode by drop-casting inks, using Nafion as binder agent. We used Na-exchanged Nafion to avoid possible corrosion of the hydroxides due to the strong acidity of the commercially available solution. Alkaline Nafion was prepared according to the procedure reported in the literature, ${ }^{34}$ by mixing 2 parts in volume of commercially available 5 wt $\%$ Nafion solution with 1 part of $0.1 \mathrm{M} \mathrm{NaOH}$, which is reported to have $\mathrm{pH} \sim 11$. The preparation of the inks is similar to previously reported methods to immobilize OER catalysts for RDE experiments, ${ }^{15,17}$ with concentrations of $5 \mathrm{mg}_{\mathrm{DH}} \mathrm{mL}_{\text {ink }}{ }^{-1}$ and 1 $\mathrm{mg}_{\text {Nafion }} \mathrm{mL}_{\text {ink }}{ }^{-1}$. The inks were prepared in absolute ethanol, first dispersing the $\mathrm{DH}$ within the solvent by sonication for 30 min and subsequently adding the Na-exchanged Nafion, followed by $20 \mathrm{~min}$ of further sonication. The catalysts were drop-casted on the Au disk to give a final loading of $75 \mu \mathrm{g}_{\mathrm{DH}}$ $\mathrm{cm}_{\text {disk }}{ }^{-2}$ and dried under vacuum, where $\mathrm{cm}_{\text {disk }}{ }^{2}$ accounts for the geometrical surface area of the disk.

The catalytic activity is reported as current density in $\mathrm{mA}$ $\mathrm{cm}_{\text {oxide }}{ }^{-2}$, where $\mathrm{cm}_{\text {oxide }}{ }^{2}$ is the real surface area of the films, calculated from pseudocapacitance measurements ${ }^{12,35}$ in the potential region $0.9-1.0 \mathrm{~V}$ vs $\mathrm{RHE}$; the specific capacitance used for this measurement was $60 \mu \mathrm{F} \mathrm{cm} \mathrm{cm}^{-2}$. 35

\section{RESULTS AND DISCUSSION}

The advantageous catalytic ${ }^{36}$ and electrocatalytic ${ }^{10}$ properties of nickel-containing oxides are well documented. In particular, recent theoretical studies ${ }^{18,24,32,37}$ have shown the high activity of nickel-containing oxides for the OER. In those studies, $\mathrm{NiO}$ has been reported to have an activity close to optimal in Sabatier-type analyses. To confirm this observation, in Figure 2 we provide the calculated activities for the entire range of oxides between $\mathrm{CaO}$ and $\mathrm{CuO}$. The descriptor used in the figure is the difference between the adsorption energies of $* \mathrm{O}$ and $* \mathrm{OH}$, which is advantageous because it tunes simultaneously two adsorption energies (through their difference), instead of only one. Note that the existence of scaling relationships among $* \mathrm{O}, * \mathrm{OH}$, and $* \mathrm{OOH}$ implies proportional variations of their differences. ${ }^{38}$ Another advantage of this descriptor is that the points in the right leg of the volcano plot do not show scattering, ${ }^{18}$ as evidenced in Figures 2 and 3. Alternatively, parameters different from adsorption energies have been used to describe activity trends on oxides, for instance bulk energetics, ${ }^{39}$ and recent work has shown the correspondence between these parameters and adsorption energies. $^{37}$ 


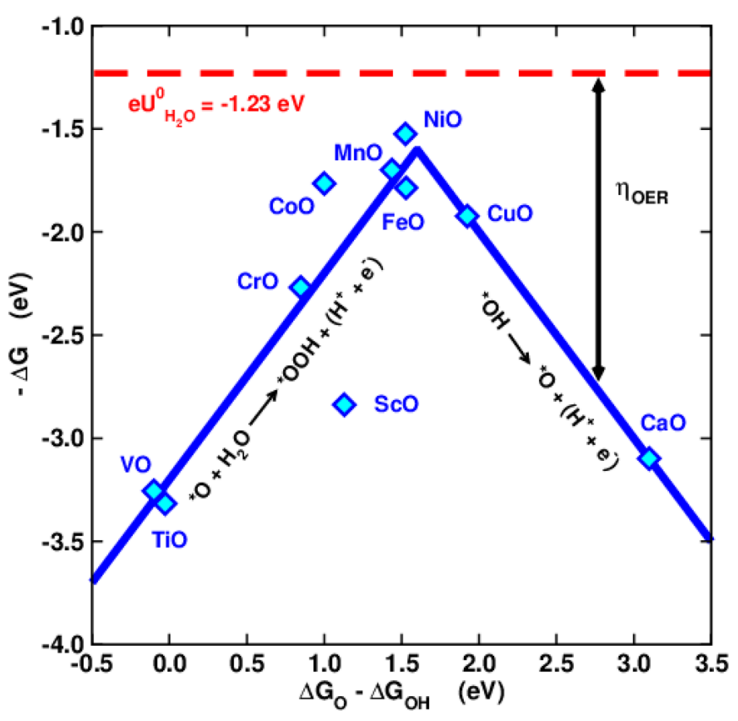

Figure 2. Sabatier-type volcano plot for the pristine (001) surfaces of the monoxides (see Figure 1.a) in the range between $\mathrm{CaO}$ and $\mathrm{CuO}$. The descriptor in the $x$ axis is the difference between the adsorption energies of oxygen and hydroxyl. The vertical differences between the red line and the blue lines and points provide an estimation of the oxygen evolution overpotential on the oxides. The potential-limiting steps are provided in black: the left leg of the volcano (strong binding side) is limited by the transformation of $* \mathrm{O}$ into $* \mathrm{OOH}$, while the right leg (weak binding side) is limited by the transformation of $* \mathrm{OH}$ into ${ }^{*} \mathrm{O}$ (following ref 18 ).

The trends in Figure 2 follow a volcano-shaped curve with the lowest overpotential corresponding to NiO. Additionally, $\mathrm{MnO}, \mathrm{CoO}, \mathrm{FeO}$, and $\mathrm{CuO}$ are predicted to show fairly high activities. However, it is not certain whether the active sites of these oxides under OER conditions correspond to those of the pristine oxide. For instance, the presence of oxyhydroxide phases at the potential and $\mathrm{pH}$ ranges of interest for the OER has been reported on $\mathrm{Co}, \mathrm{Ni}$, and $\mathrm{Au}$ oxides. ${ }^{32,40-42}$
Consequently, these observations set up an appropriate background to pose two important questions. First, is the pristine (001) surface with low adsorbate coverage a good representation of $\mathrm{NiO}$ during the OER? Second, why is it possible to improve the activity of $\mathrm{NiO}$ by doping/mixing with other oxides, if $\mathrm{NiO}$ is already expected to be the most active monoxide? In the following we will address these questions both theoretically and experimentally and show that the answers are intimately related.

The descriptor in the $x$ axis in Figure 2, that is the difference between the adsorption energies of $* \mathrm{O}$ and $* \mathrm{OH}$, marks the top of the activity plot at approximately $1.6 \mathrm{eV}$. Pristine $\mathrm{NiO}$ has a difference of $\sim 1.5 \mathrm{eV}$, whence its low predicted overpotential. When the $\mathrm{NiO}$ surface is further oxidized and hydrated to produce active sites of the $\mathrm{NiOOH}$ type, the formal oxidation state of $\mathrm{Ni}$ changes from +2 to +3 . This is reflected in a considerable weakening of the adsorption energies, so that the descriptor is $\sim 1.84 \mathrm{eV}$ for $\mathrm{NiOOH}$. Note that similar decreases in binding strength have been reported for transition-metal oxides, including those of $\mathrm{Ni}$, as the metal center is oxidized. ${ }^{38}$ Hence, the value of the descriptor for pristine $\mathrm{NiO}$ is $0.1 \mathrm{eV}$ more negative than that required to be at the top of the volcano, whereas the value for the oxyhydroxide is $0.24 \mathrm{eV}$ more positive than optimal. This difference of $0.24 \mathrm{eV}$ from thermodynamic optimality suggests that significant improvements can be made to NiOOH-like active sites in terms of binding to OER intermediates. The design principle in this case is simple: $\mathrm{NiOOH}$ needs to be modified so that the difference in the adsorption energies of $* \mathrm{O}$ and $* \mathrm{OH}$ is decreased by approximately $0.24 \mathrm{eV}$.

We used this design criterion to assess the OER activity of $\mathrm{NiMOOH}$ sites with octahedral symmetry, with $\mathrm{M}=\mathrm{Cr}, \mathrm{Mn}$, $\mathrm{Fe}, \mathrm{Co}, \mathrm{Cu}, \mathrm{Zn}$. The results are shown in Figure 3, where $\mathrm{NiOOH}, \mathrm{NiO}$ (from Figure 2), and $\mathrm{IrO}_{2}$ (adapted from ref 18) are included for the sake of comparison. The figure includes the effect of doping on $\mathrm{Ni}$ sites and also the effect of the $\mathrm{NiO}$ lattice on the $\mathrm{M}$ sites. Figure $3 \mathrm{a}$ shows that the doping effects on $\mathrm{Ni}$

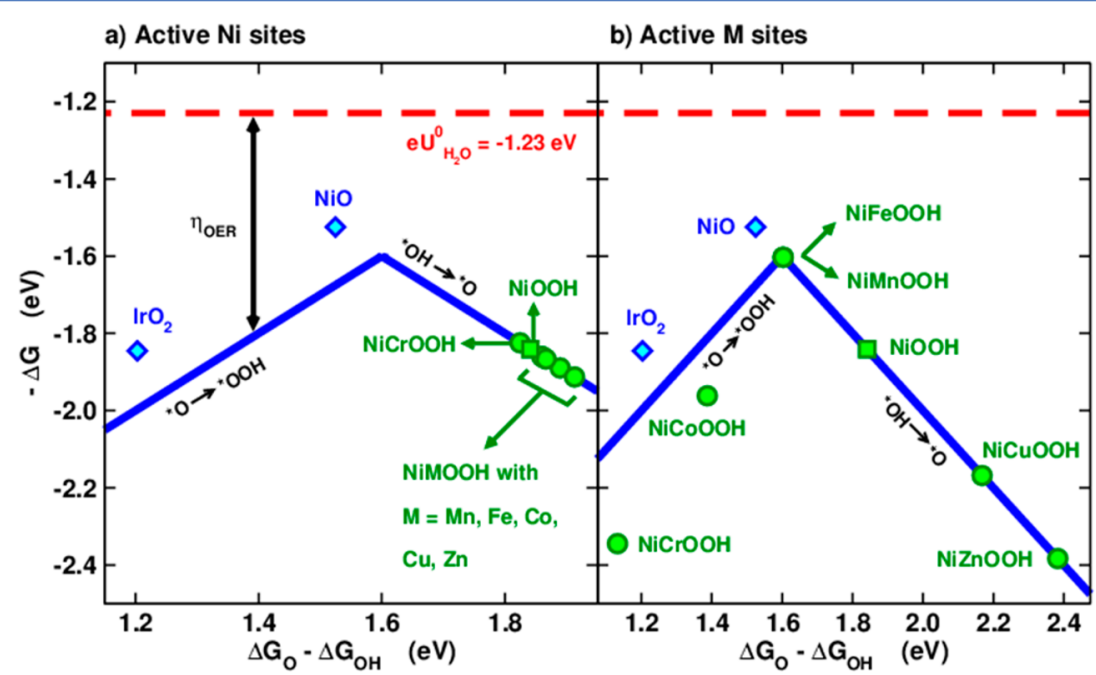

Figure 3. Sabatier-type volcano plots for Ni-based oxyhydroxide sites doped with transition metals (see Figure $1 \mathrm{~b}, \mathrm{c}$ ). The surfaces were doped with $\mathrm{Cr}, \mathrm{Mn}, \mathrm{Fe}, \mathrm{Co}, \mathrm{Cu}$, and $\mathrm{Zn}$. The descriptors and catalytic activities were calculated analogously to those in Figure 2 . The vertical differences between the red line and the blue lines and/or the points provide an estimation of the oxygen evolution overpotential on the oxides $\left(\eta_{\text {OER }}\right)$. (a) Effect of doping on $\mathrm{Ni}$ sites. It is observed that doping with $\mathrm{Mn}, \mathrm{Fe}, \mathrm{Co}, \mathrm{Cu}$, and $\mathrm{Zn}$ causes slight increases in the OER overpotential of Ni sites, while doping with $\mathrm{Cr}$ causes a slight decrease. (b) Activity of dopants in a NiOOH lattice. The overpotentials are rather different depending on the transition metal, and $\mathrm{Fe}$ and $\mathrm{Mn}$ are near the top of the volcano. Pristine $\mathrm{NiO}$ (from Figure 2) and $\mathrm{IrO}_{2}$ (adapted from ref 18) are provided for comparison as blue rhombs, while $\mathrm{NiOOH}$ appears as a green square. 
are modest, and slight increases on the OER overpotential with respect to $\mathrm{NiOOH}$ are observed for $\mathrm{Mn}, \mathrm{Fe}, \mathrm{Co}, \mathrm{Cu}$, and $\mathrm{Zn}$ doping, while $\mathrm{Cr}$ doping decreases the overpotential. Thus, taking into account the accuracy of DFT at the GGA level, that is $0.2 \mathrm{eV},{ }^{43}$ it is possible to say that the predicted overpotentials of $\mathrm{Ni}$ sites in $\mathrm{NiMOOH}$ are similar to those of $\mathrm{NiOOH}$, with only $\mathrm{Cr}$ doping reducing the overpotential, but the small differences make it hard to provide more detailed predictions. Note that, although $\mathrm{NiO}$ is usually antiferromagnetic with spin alignment in the (111) plane, ${ }^{24}$ the addition of dopants results in ferrimagnetic configurations and, in some cases, the spin alignments switch to the (100) plane. Therefore, the spin state of the surface is important for the determination of the trends.

On the other hand, the effects of the $\mathrm{NiO}$ lattice on the $\mathrm{M}$ sites are rather different, depending on the transition metals. Basically, there are two kinds of dopants in the studied group of transition metals: first, $\mathrm{Mn}$ and $\mathrm{Fe}$, which possess nearly optimal binding energies and hence reduce the predicted OER overpotential, and second, $\mathrm{Cr}, \mathrm{Co}, \mathrm{Cu}$, and $\mathrm{Zn}$, which increase the OER overpotential.

In summary, the addition of $\mathrm{Cr}, \mathrm{Mn}$, and $\mathrm{Fe}$ should enhance the OER activity of $\mathrm{NiOOH}$, while $\mathrm{Co}, \mathrm{Cu}$, and $\mathrm{Zn}$ will have overpotentials similar to or larger than that of $\mathrm{NiOOH}$.

The noteworthy enhancing effect of $\mathrm{Fe}$ on the catalytic activity of nickel hydroxide has been reported in the literature, ${ }^{13,20,21}$ although the explanation for such enhancement is still a matter of debate. ${ }^{13,24,32,44}$ Although the ligand effect is well-known in metal electrocatalysis and has been systematically quantified and exploited, ${ }^{45,46}$ the effect of doping in oxide electrocatalysis is less well documented, as its magnitude and direction depend on the interactions between the host and the guest metals in a stretched lattice, in addition to the interactions of the metals and lattice oxygen. ${ }^{47,48}$ In our particular case, we observe that the ligand effect is small on $\mathrm{Ni}$ sites (Figure 3a), while it is significant on $M$ sites (Figure $3 b$ ). This is intuitive, as $\mathrm{M}$ is embedded in a lattice where the $\mathrm{M}-\mathrm{O}$ distances are different from those of its pure oxide. Furthermore, our results are in agreement with those of Bell and co-workers, ${ }^{24}$ who concluded that the metal site responsible for the significant enhancement of the catalytic activity of $\mathrm{NiFeOOH}$ in comparison to $\mathrm{NiOOH}$ is $\mathrm{Fe}$, rather than $\mathrm{Ni}$. We predict the same for $\mathrm{NiMnOOH}$, in which $\mathrm{Mn}$ will be the active metal. Conversely, in $\mathrm{NiCrOOH}$, which is the other surface that may reduce the OER overpotential, $\mathrm{Ni}$ is the active site, rather than $\mathrm{Cr}$, and the enhancement effect should be lower than that of $\mathrm{Fe}$, on the basis of Figure 3a.

It is also important to note that the active sites in Figure 1c possess full coverage of oxygenated species during the OER. Coverage effects are sometimes important, as lateral adsorbate-adsorbate interactions may weaken or strengthen the adsorption energies. ${ }^{49}$ The adsorbates covering the surface can be inferred from volcano plots, considering the following. (a) $\mathrm{NiOOH}$ is on the weak side of the volcano in Figure 3; thus, its potential-limiting step is the transformation of $* \mathrm{OH}$ into $* \mathrm{O}$, and the $\mathrm{Ni}$ sites should be covered with $* \mathrm{OH}$ under OER conditions. The situation is analogous for $\mathrm{NiCuOOH}$ and $\mathrm{NiZnOOH}$. (b) The potential-limiting step for $\mathrm{Cr}, \mathrm{Mn}, \mathrm{Fe}$, and Co monoxides is the transformation of $* \mathrm{O}$ into $* \mathrm{OOH}$. Thus, these $\mathrm{M}$ sites at $\mathrm{NiMOOH}$ surfaces will normally be covered with $* \mathrm{O}$ under OER conditions.

Experimentally, one can start assessing the effect of transition metals on NiO-based catalysts by analogy to well-defined mixed oxides. In this vein, Landon et al. have proposed that $\mathrm{NiFe}_{2} \mathrm{O}_{4}$ spinel has a significant role in the enhancement of the catalytic activity of mixed $\mathrm{NiFe}$ oxides. ${ }^{44}$ The findings of $\mathrm{Li}$ and Selloni controvert this statement, as they found through DFT calculations that $\mathrm{NiFe}_{2} \mathrm{O}_{4}$ is active for the OER, but its activity is noticeably lower than that of $\mathrm{Fe}$-doped $\mathrm{Ni}$ oxides. ${ }^{32}$ To evaluate these conflicting claims, we induced the thermal decomposition of the $\mathrm{NiFe} \mathrm{DH}$ so as to obtain the spinel structure, as shown in the XRD pattern in Figure S1 in the Supporting Information, and measured its catalytic activity toward electrochemical water oxidation. The results are summarized in Figure 4, where it is observed that the onset

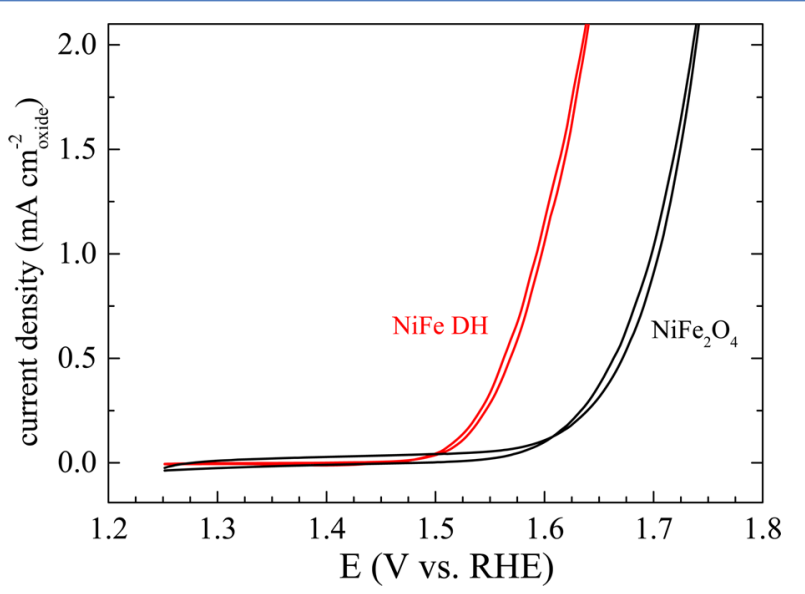

Figure 4. Cyclic voltammetry for the oxygen evolution reaction in 0.1 $\mathrm{M} \mathrm{KOH}$ of $\mathrm{NiFe} \mathrm{DH}$ and $\mathrm{NiFe}_{2} \mathrm{O}_{4}$ immobilized on Au. Experiments were performed under hydrodynamic conditions $(\omega=1500 \mathrm{rpm}, \nu=$ $0.01 \mathrm{~V} \mathrm{~s}^{-1}$ ). The red line shows the catalytic activity measured on the $\mathrm{NiFe} \mathrm{DH}$, and the black line shows the activity measured on the $\mathrm{NiFe}_{2} \mathrm{O}_{4}$, obtained after thermal decomposition of the $\mathrm{NiFe} \mathrm{DH}$ at $600{ }^{\circ} \mathrm{C}$.

of the reaction on $\mathrm{NiFe}_{2} \mathrm{O}_{4}$ is located at more positive potentials in comparison to $\mathrm{NiFe} \mathrm{DH}$. We conclude, therefore, that the spinel phase is indeed less active than the double hydroxide and that the active sites in both catalysts must be different.

The effect of Fe doping on the catalytic activity of $\mathrm{NiFe} \mathrm{DH}$ was studied for Fe contents in the range $25-75 \%$ (see Figure S3 in the Supporting Information). We observed that the highest catalytic activity is reached at $50 \%$ of Fe doping; thus, this composition was used to study the doping effects of the other transition metals both experimentally and computationally.

With the theoretical results of Figure 3 in mind, we conducted OER experiments on $\mathrm{NiOOH}$ doped with $50 \%$ $\mathrm{Cr}, \mathrm{Mn}, \mathrm{Fe}, \mathrm{Co}, \mathrm{Cu}$, and $\mathrm{Zn}$ and on $\mathrm{Ni}(\mathrm{OH})_{2}$, to be used as a benchmark. The real composition of these catalysts was measured by ICP-AES and is shown in Table S1 in the Supporting Information. We find that the $\mathrm{Ni} / \mathrm{M}$ ratio is close to 1 in all cases. Figure 5 shows the polarization curves obtained for the oxygen evolution on the different catalysts. There is a clear effect of the $3 \mathrm{~d}$ transition metals in the catalytic activity toward oxygen evolution, measured in terms of current density; in the case of $\mathrm{Mn}, \mathrm{Cr}$, and $\mathrm{Fe}$, the OER potential to reach 0.5 $\mathrm{mA} \mathrm{cm}{ }^{-2}$ is reduced by approximately 60,100 , and $130 \mathrm{mV}$, respectively, in comparison to $\mathrm{Ni}(\mathrm{OH})_{2}$. In contrast, $\mathrm{Co}, \mathrm{Cu}$, and $\mathrm{Zn} \mathrm{DHs}$ increase the overpotential. Interestingly, NiMn $\mathrm{DH}$ is predicted by our theoretical analysis to be as active as $\mathrm{NiFe} \mathrm{DH}$. Note, however, that the XRD patterns of the $\mathrm{Mn}$ 


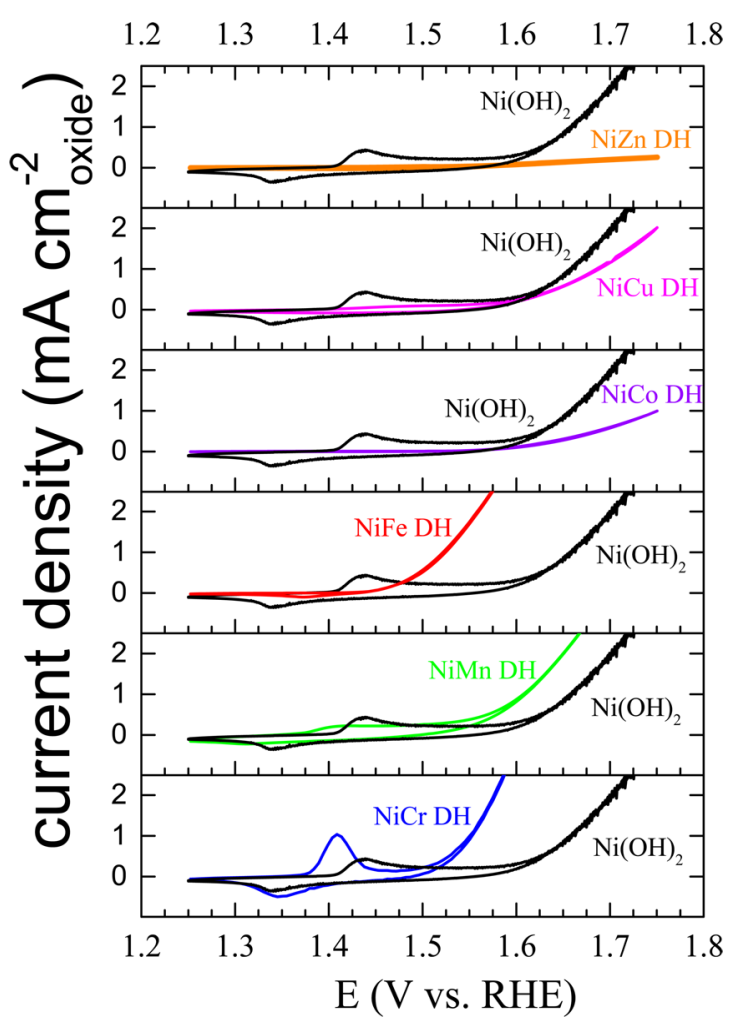

Figure 5. Cyclic voltammetry for the OER in $0.1 \mathrm{M} \mathrm{KOH}$ of nickelbased DH immobilized on Au. Experiments were performed under hydrodynamic conditions $\left(\omega=1500 \mathrm{rpm}, \nu=0.01 \mathrm{~V} \mathrm{~s}^{-1}\right)$. The black line shows the activity of $\mathrm{Ni}(\mathrm{OH})_{2}$, presented as a benchmark of the catalytic activity.

DH (see Figure S2 in the Supporting Information) suggest that the synthesis method produced a separate phase of $\mathrm{MnCO}_{3}$ and a minor amount of the double hydroxide, which was also confirmed by FTIR measurements (see Figure S4 in the Supporting Information). Segregation of $\mathrm{MnCO}_{3}$ during the synthesis process may explain the lower than expected catalytic activity observed for the NiMn DH due to a high amount of amorphous sites in the external layers of the hydroxide structure, which are the most catalytically active.

Note in passing that, in the case of Co doping, it is observed that $\mathrm{Ni}(\mathrm{OH})_{2}$ segregates from the mixed hydroxide (see Figure S2 in the Supporting Information). This, however, has no influence on our conclusions, as $\mathrm{NiCoOOH}$ is not predicted theoretically to have overpotentials lower than those of $\mathrm{NiOOH}$.

The catalytic activity of the $\mathrm{NiFe} \mathrm{DH}$ toward electrochemical oxygen evolution in alkaline media was also compared with that of $\mathrm{IrO}_{2}$, which is normally used as a benchmark for this reaction. ${ }^{12}$ The double hydroxide possesses higher catalytic activity than the benchmark (see Figure S5 in the Supporting Information), and the activity is comparable to that reported for $\mathrm{NiFe}$ DH supported on carbon nanotubes. ${ }^{14,22}$ Importantly, the preparation procedure used in this work is much simpler and can be applied to the elaboration of several other double hydroxides. Such a method might prove advantageous for the large-scale production of catalysts. Moreover, the procedure shows that the enhanced activity of $\mathrm{NiFe}$ double hydroxides is mostly due to sites composed of $\mathrm{Ni}, \mathrm{Fe} / \mathrm{Cr}$, and oxygenated species distributed spatially in an octahedral fashion.
We have also estimated the Faradaic efficiency toward electrochemical water oxidation catalyzed by $\mathrm{NiFe} \mathrm{DH}$ by rotating ring-disk electrode (RRDE) measurements. ${ }^{12}$ Figure 6

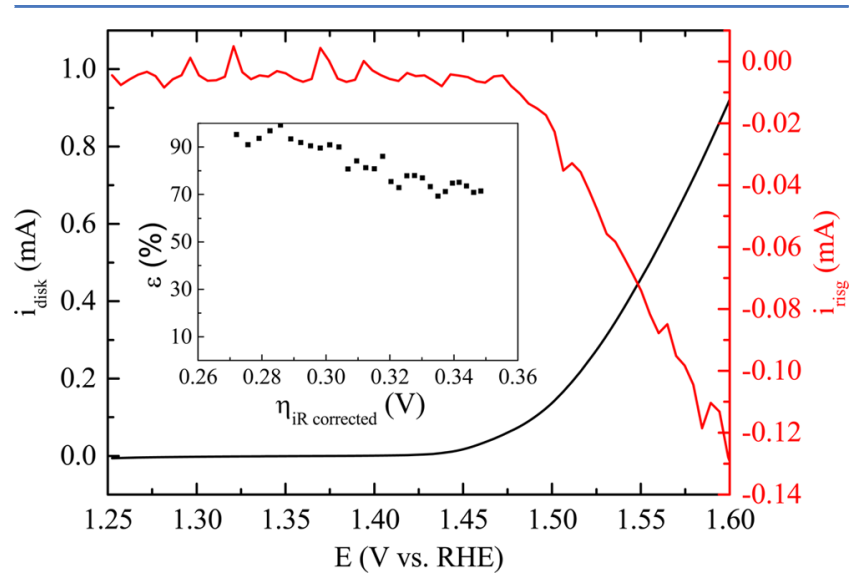

Figure 6. Polarization curve for OER in $0.1 \mathrm{M} \mathrm{KOH}$ of nickel-based $\mathrm{DH}$ immobilized on Au. Experiments were performed in RRDE configuration (Pt ring at $0.45 \mathrm{~V}$ vs RHE) at $\omega=1500 \mathrm{rpm}$ and $\nu=$ $0.01 \mathrm{~V} \mathrm{~s}^{-1}$. Inset: Faradaic efficiency $(\varepsilon)$ as a function of the potential applied to the disk.

shows that the $\mathrm{NiFe}$ catalyst splits water with a Faradaic efficiency of $>90 \%$ at $270 \mathrm{mV}$ of overpotential (see the Supporting Information for details about the calculation of the efficiency).

Finally, we have also addressed the important matter of the catalyst stability and durability under working conditions. To do so, we used McCrory et al.'s method ${ }^{12}$ (see section S6 in the Supporting Information) and conclude that $\mathrm{NiFe} \mathrm{DHs}$ are more stable than $\mathrm{IrO}_{x}$ nanoparticles, which are typically used as benchmarks.

\section{CONCLUSIONS}

We have presented simple guidelines for the rational design of Ni-based double hydroxides with transition metals, to catalyze the electrochemical water oxidation reaction. These rules allowed us to understand the improving effect of $\mathrm{Cr}, \mathrm{Mn}$, and $\mathrm{Fe}$ on the catalytic activity of the Ni-based double hydroxides toward oxygen evolution and the deleterious effect of $\mathrm{Co}, \mathrm{Cu}$, and $\mathrm{Zn}$. The active sites are suggested to be of the oxyhydroxide type (that is, $\mathrm{NiMOOH}$, where $\mathrm{M}$ is a transition-metal dopant), in which the metals form octahedral $\mathrm{NiO}_{6}$ and $\mathrm{MO}_{6}$ complexes. Our computational results go beyond the state of the art by considering high-coverage regimes. We did so for each double hydroxide by covering the surface with different species depending on their location on the volcano plot. Moreover, we have made experimental oneby-one comparisons between $\mathrm{Ni}(\mathrm{OH})_{2}$ and the double hydroxides and between the double hydroxides and state-ofthe-art $\mathrm{IrO}_{2}$ nanoparticles. At a reference current density of 0.5 $\mathrm{mA} \mathrm{cm}{ }^{-2}$ we observed that, on the one hand, $\mathrm{Mn}, \mathrm{Cr}$, and $\mathrm{Fe}$ reduce the potential needed to reach the reference current density by 60,100 , and $130 \mathrm{mV}$, respectively, with respect to $\mathrm{Ni}(\mathrm{OH})_{2}$. On the other hand, the potential to reach the reference current density is reduced by 160, 190, and $230 \mathrm{mV}$, in comparison to $\mathrm{IrO}_{2}$ nanoparticles, by doping with $\mathrm{Mn}, \mathrm{Cr}$, and $\mathrm{Fe}$, respectively. These two comparisons show that our simple preparation method renders catalysts that are substantially more active than those representing the state of the 
art. According to the DFT-based analysis presented here, the effects of $\mathrm{Fe}, \mathrm{Mn}$, and $\mathrm{Cr}$ doping are different, as $\mathrm{Fe}$ and $\mathrm{Mn}$ are the active sites in $\mathrm{NiFeOOH}$ and $\mathrm{NiMnOOH}$ and $\mathrm{Ni}$ is the active site in $\mathrm{NiCrOOH}$.

The NiFe DHs prepared here show significantly higher catalytic activity and stability toward electrochemical water oxidation in comparison to $\mathrm{IrO}_{2}$, with over $90 \%$ efficiency for electrochemical $\mathrm{O}_{2}$ generation. Their activity is comparable to that of $\mathrm{NiFe} \mathrm{DHs}$ obtained through different procedures, while using a considerably simpler preparation method.

These conclusions must be seen in the light of the experimental uncertainty about the exact structure of the surfaces in combination with the accuracy of DFT. Therefore, the significance of this study lies mainly in the guidelines and broader understanding it provides in terms of trends in catalytic activity.

\section{ASSOCIATED CONTENT}

\section{S Supporting Information}

The Supporting Information is available free of charge on the ACS Publications website at DOI: 10.1021/acscatal.5b01638.

XRD and infrared characterization of the nickel-based double hydroxides, cyclic voltammetry showing the effect of iron doping in $\mathrm{NiFe} \mathrm{DH}$ on its OER activity and comparing the NiFe DH OER activity versus $\mathrm{IrO}_{2}$ nanoparticles, stability test of $\mathrm{NiFe} \mathrm{DH}$ under anodic conditions, details about the Faradaic efficiency and formulas for the calculation of adsorption energies, and elemental analysis of the nickel-based double hydroxides by ICP-AES (PDF)

\section{AUTHOR INFORMATION}

\section{Corresponding Authors}

*E-mail for M.T.M.K.: m.koper@lic.leidenuniv.nl.

*E-mail for F.C.-V.: f.calle.vallejo@lic.leidenuniv.nl.

\section{Notes}

The authors declare no competing financial interest.

\section{ACKNOWLEDGMENTS}

F.C.-V. acknowledges funding from The Netherlands Organization for Scientific Research (NWO), Veni project number 722.014.009. This work was also supported by The Netherlands Organization for Scientific Research (NWO) and in part by the BioSolar Cells open innovation consortium, supported by the Dutch Ministry of Economic Affairs, Agriculture and Innovation. The Stichting Nationale Computerfaciliteiten (NCF) is also acknowledged for the use of their supercomputer facilities, with financial support from NWO. O.D.-M. thanks Prof. E. Bouwman for the use of the X-ray Diffraction and ICPAES facilities in her group at Leiden University and Dr. W. T. $\mathrm{Fu}$ for useful discussions on the XRD results. Jos van Brussel is kindly acknowledged for assisting with the elemental analysis by ICP-AES.

\section{REFERENCES}

(1) Hoffert, M. I.; Caldeira, K.; Jain, A. K.; Haites, E. F.; Harvey, L. D. D.; Potter, S. D.; Schlesinger, M. E.; Schneider, S. H.; Watts, R. G.; Wigley, T. M. L.; Wuebbles, D. J. Energy implications of future stabilization of atmospheric CO2 content. Nature 1998, 395 (6705), 881-884.
(2) Olah, G. A.; Prakash, G. K.; Goeppert, A. Anthropogenic chemical carbon cycle for a sustainable future. J. Am. Chem. Soc. 2011, 133 (33), 12881-12898.

(3) Crabtree, G. W.; Dresselhaus, M. S.; Buchanan, M. V. The hydrogen economy. Phys. Today 2004, 57 (12), 39-44.

(4) McGlade, C.; Ekins, P. The geographical distribution of fossil fuels unused when limiting global warming to $2{ }^{\circ} \mathrm{C}$. Nature 2015, 517 (7533), 187-190.

(5) Lewis, N. S.; Nocera, D. G. Powering the planet: chemical challenges in solar energy utilization. Proc. Natl. Acad. Sci. U. S. A. 2006, 103 (43), 15729-15735.

(6) Bensaid, S.; Centi, G.; Garrone, E.; Perathoner, S.; Saracco, G. Towards artificial leaves for solar hydrogen and fuels from carbon dioxide. ChemSusChem 2012, 5 (3), 500-521.

(7) Hermans, L. J. F. Energy Survival Guide; BetaText/Leiden University Press: Amsterdam, 2011; p 184.

(8) Koper, M. T. M. Thermodynamic theory of multi-electron transfer reactions: Implications for electrocatalysis. J. Electroanal. Chem. 2011, 660 (2), 254-260.

(9) Dau, H.; Limberg, C.; Reier, T.; Risch, M.; Roggan, S.; Strasser, P. The Mechanism of Water Oxidation: From Electrolysis via Homogeneous to Biological Catalysis. ChemCatChem 2010, 2 (7), 724-761.

(10) Matsumoto, Y.; Sato, E. Electrocatalytic properties of transition metal oxides for oxygen evolution reaction. Mater. Chem. Phys. 1986, 14 (5), 397-426.

(11) Lee, Y.; Suntivich, J.; May, K. J.; Perry, E. E.; Shao-Horn, Y. Synthesis and Activities of Rutile $\mathrm{IrO} 2$ and $\mathrm{RuO} 2$ Nanoparticles for Oxygen Evolution in Acid and Alkaline Solutions. J. Phys. Chem. Lett. 2012, 3 (3), 399-404.

(12) McCrory, C. C.; Jung, S.; Peters, J. C.; Jaramillo, T. F. Benchmarking heterogeneous electrocatalysts for the oxygen evolution reaction. J. Am. Chem. Soc. 2013, 135 (45), 16977-16987.

(13) Corrigan, D. A. The Catalysis of the Oxygen Evolution Reaction by Iron Impurities in Thin Film Nickel Oxide Electrodes. J. Electrochem. Soc. 1987, 134 (2), 377-384.

(14) Gong, M.; Li, Y.; Wang, H.; Liang, Y.; Wu, J. Z.; Zhou, J.; Wang, J.; Regier, T.; Wei, F.; Dai, H. An advanced Ni-Fe layered double hydroxide electrocatalyst for water oxidation. J. Am. Chem. Soc. 2013, 135 (23), 8452-8455.

(15) Grimaud, A.; May, K. J.; Carlton, C. E.; Lee, Y. L.; Risch, M.; Hong, W. T.; Zhou, J.; Shao-Horn, Y. Double perovskites as a family of highly active catalysts for oxygen evolution in alkaline solution. Nat. Commun. 2013, 4, 2439.

(16) Song, F.; Hu, X. Exfoliation of layered double hydroxides for enhanced oxygen evolution catalysis. Nat. Commun. 2014, 5, 4477.

(17) Suntivich, J.; May, K. J.; Gasteiger, H. A.; Goodenough, J. B.; Shao-Horn, Y. A perovskite oxide optimized for oxygen evolution catalysis from molecular orbital principles. Science 2011, 334 (6061), 1383-1385.

(18) Man, I. C.; Su, H.-Y.; Calle-Vallejo, F.; Hansen, H. A.; Martínez, J. I.; Inoglu, N. G.; Kitchin, J.; Jaramillo, T. F.; Nørskov, J. K.; Rossmeisl, J. Universality in Oxygen Evolution Electrocatalysis on Oxide Surfaces. ChemCatChem 2011, 3 (7), 1159-1165.

(19) Oliva, P.; Leonardi, J.; Laurent, J. F.; Delmas, C.; Braconnier, J. J.; Figlarz, M.; Fievet, F.; Guibert, A. d. Review of the structure and the electrochemistry of nickel hydroxides and oxy-hydroxides. J. Power Sources 1982, 8 (2), 229-255.

(20) Młynarek, G.; Paszkiewicz, M.; Radniecka, A. The effect of ferric ions on the behaviour of a nickelous hydroxide electrode. J. Appl. Electrochem. 1984, 14 (2), 145-149.

(21) Corrigan, D. A.; Bendert, R. M. Effect of Coprecipitated Metal Ions on the Electrochemistry of Nickel Hydroxide Thin Films: Cyclic Voltammetry in $1 \mathrm{M} \mathrm{KOH}$. J. Electrochem. Soc. 1989, 136 (3), $723-$ 728.

(22) Gong, M.; Dai, H. A mini review of NiFe-based materials as highly active oxygen evolution reaction electrocatalysts. Nano Res. 2015, 8, 23-39. 
(23) Lu, Z.; Xu, W.; Zhu, W.; Yang, Q.; Lei, X.; Liu, J.; Li, Y.; Sun, X.; Duan, $\mathrm{X}$. Three-dimensional NiFe layered double hydroxide film for high-efficiency oxygen evolution reaction. Chem. Commun. 2014, 50 (49), 6479-6482.

(24) Friebel, D.; Louie, M. W.; Bajdich, M.; Sanwald, K. E.; Cai, Y.; Wise, A. M.; Cheng, M.-J.; Sokaras, D.; Weng, T.-C.; Alonso-Mori, R.; Davis, R. C.; Bargar, J. R.; Nørskov, J. K.; Nilsson, A.; Bell, A. T. Identification of Highly Active $\mathrm{Fe}$ Sites in $(\mathrm{Ni}, \mathrm{Fe}) \mathrm{OOH}$ for Electrocatalytic Water Splitting. J. Am. Chem. Soc. 2015, 137 (3), $1305-1313$.

(25) Norskov, J. K.; Bligaard, T.; Rossmeisl, J.; Christensen, C. H. Towards the computational design of solid catalysts. Nat. Chem. 2009, 1 (1), 37-46.

(26) Kresse, G.; Furthmüller, J. Efficient iterative schemes for $\backslash$ textit $\{\mathrm{ab}$ initio $\}$ total-energy calculations using a plane-wave basis set. Phys. Rev. B: Condens. Matter Mater. Phys. 1996, 54 (16), 1116911186.

(27) Hammer, B.; Hansen, L. B.; Nørskov, J. K. Improved adsorption energetics within density-functional theory using revised PerdewBurke-Ernzerhof functionals. Phys. Rev. B: Condens. Matter Mater. Phys. 1999, 59 (11), 7413-7421.

(28) Vanderbilt, D. Soft self-consistent pseudopotentials in a generalized eigenvalue formalism. Phys. Rev. B: Condens. Matter Mater. Phys. 1990, 41 (11), 7892-7895.

(29) Methfessel, M.; Paxton, A. T. High-precision sampling for Brillouin-zone integration in metals. Phys. Rev. B: Condens. Matter Mater. Phys. 1989, 40 (6), 3616-3621.

(30) Calle-Vallejo, F.; Koper, M. T. M. First-principles computational electrochemistry: Achievements and challenges. Electrochim. Acta 2012, 84 (0), 3-11.

(31) Nørskov, J. K.; Rossmeisl, J.; Logadottir, A.; Lindqvist, L.; Kitchin, J. R.; Bligaard, T.; Jónsson, H. Origin of the Overpotential for Oxygen Reduction at a Fuel-Cell Cathode. J. Phys. Chem. B 2004, 108 (46), 17886-17892.

(32) Li, Y.-F.; Selloni, A. Mechanism and Activity of Water Oxidation on Selected Surfaces of Pure and Fe-Doped NiOx. ACS Catal. 2014, 4 (4), 1148-1153.

(33) Cavani, F.; Trifirò, F.; Vaccari, A. Hydrotalcite-type anionic clays: Preparation, properties and applications. Catal. Today 1991, 11 (2), 173-301.

(34) Suntivich, J.; Gasteiger, H. A.; Yabuuchi, N.; Shao-Horn, Y. Electrocatalytic Measurement Methodology of Oxide Catalysts Using a Thin-Film Rotating Disk Electrode. J. Electrochem. Soc. 2010, 157 (8), B1263-B1268.

(35) Trasatti, S.; Petrii, O. A. Real surface area measurements in electrochemistry. J. Electroanal. Chem. 1992, 327 (1-2), 353-376.

(36) McFarland, E. W.; Metiu, H. Catalysis by Doped Oxides. Chem. Rev. 2013, 113 (6), 4391-4427.

(37) Calle-Vallejo, F.; Díaz-Morales, O. A.; Kolb, M. J.; Koper, M. T. M. Why Is Bulk Thermochemistry a Good Descriptor for the Electrocatalytic Activity of Transition Metal Oxides? ACS Catal. 2015, $5,869-873$.

(38) Calle-Vallejo, F.; Inoglu, N. G.; Su, H.-Y.; Martinez, J. I.; Man, I. C.; Koper, M. T. M.; Kitchin, J. R.; Rossmeisl, J. Number of outer electrons as descriptor for adsorption processes on transition metals and their oxides. Chem. Sci. 2013, 4 (3), 1245-1249.

(39) Trasatti, S. Electrocatalysis in the anodic evolution of oxygen and chlorine. Electrochim. Acta 1984, 29 (11), 1503-1512.

(40) Bajdich, M.; García-Mota, M.; Vojvodic, A.; Nørskov, J. K.; Bell, A. T. Theoretical Investigation of the Activity of Cobalt Oxides for the Electrochemical Oxidation of Water. J. Am. Chem. Soc. 2013, 135 (36), 13521-13530.

(41) Chen, J.; Selloni, A. First Principles Study of Cobalt (Hydr)oxides under Electrochemical Conditions. J. Phys. Chem. C 2013, 117 (39), 20002-20006.

(42) Diaz-Morales, O.; Calle-Vallejo, F.; de Munck, C.; Koper, M. T. M. Electrochemical water splitting by gold: evidence for an oxide decomposition mechanism. Chem. Sci. 2013, 4 (6), 2334-2343.
(43) Kurth, S.; Perdew, J. P.; Blaha, P. Molecular and solid-state tests of density functional approximations: LSD, GGAs, and meta-GGAs. Int. J. Quantum Chem. 1999, 75 (4-5), 889-909.

(44) Landon, J.; Demeter, E.; İnoğlu, N.; Keturakis, C.; Wachs, I. E.; Vasić, R.; Frenkel, A. I.; Kitchin, J. R. Spectroscopic Characterization of Mixed $\mathrm{Fe}-\mathrm{Ni}$ Oxide Electrocatalysts for the Oxygen Evolution Reaction in Alkaline Electrolytes. ACS Catal. 2012, 2 (8), 1793-1801.

(45) Calle-Vallejo, F.; Koper, M. T. M.; Bandarenka, A. S. Tailoring the catalytic activity of electrodes with monolayer amounts of foreign metals. Chem. Soc. Rev. 2013, 42 (12), 5210-5230.

(46) Kitchin, J. R.; Nørskov, J. K.; Barteau, M. A.; Chen, J. G. Role of Strain and Ligand Effects in the Modification of the Electronic and Chemical Properties of Bimetallic Surfaces. Phys. Rev. Lett. 2004, 93 (15), 156801

(47) Gelatt, C. D.; Williams, A. R.; Moruzzi, V. L. Theory of bonding of transition metals to nontransition metals. Phys. Rev. B: Condens. Matter Mater. Phys. 1983, 27 (4), 2005-2013.

(48) Calle-Vallejo, F.; Martínez, J. I.; García-Lastra, J. M.; Mogensen, M.; Rossmeisl, J. Trends in Stability of Perovskite Oxides. Angew. Chem., Int. Ed. 2010, 49 (42), 7699-7701.

(49) Grabow, L.; Hvolbæk, B.; Nørskov, J. Understanding Trends in Catalytic Activity: The Effect of Adsorbate-Adsorbate Interactions for CO Oxidation Over Transition Metals. Top. Catal. 2010, 53 (5-6), 298-310. 